\title{
A Rare Case of Bilateral Proptosis
}

\author{
$\underline{\text { Joao Fernandes Serodio }}{ }^{1}$, Marta Jonet $^{1}$, Miguel Trinidade $^{1}$, Inês Coutinho ${ }^{2}$, Catarina Favas ${ }^{1}$ \\ ${ }^{1}$ Medicine IV Department, Hospital Prof. Doutor Fernando Fonseca, Amadora, Portugal \\ ${ }^{2}$ Ophthalmology Department, Hospital Prof. Doutor Fernando Fonseca, Amadora, Portugal
}

Received: 22/09/2018

Accepted: 05/10/2018

Published: 30/10/2018

How to cite this article: Fernandes Serodio J ,Jonet M, Trinidade M, Coutinho I, Favas C. A rare case of bilateral proptosis. EJCRIM 2018;5: doi:10.12890/2018_000966.

Conflicts of Interests: The Authors declare that there are no competing interests.

This article is licensed under a Commons Attribution Non-Commercial 4.0 License

\section{ABSTRACT}

A 65-year-old man presented with a 2-year history of severe bilateral proptosis, palpable lymphadenopathy and moderate hepatosplenomegaly. A blood test was positive for hepatitis $C$ infection. CT showed palpebral infiltrative lesions with regional progression through the temporal and masticatory spaces to the pharynx and hypopharynx causing almost complete airway obstruction. A palpebral biopsy was consistent with low-grade Bcl-2+ extra-nodal MALT non-Hodgkin B-cell lymphoma. The patient received six cycles of rituximabbased chemotherapy with clinical remission at 9-month follow-up. Bilateral proptosis is a rare presentation of several diseases. When brain CT excludes cavernous sinus pathology, thyroid ophthalmopathy or haematological malignancy should be considered.

\section{LEARNING POINTS}

- Bilateral proptosis is a rare presentation with a broad differential diagnosis, and is most frequently is caused by cavernous sinus disease, thyroid ophthalmopathy or haematological malignancy.

- Hepatitis C may be associated with MALT lymphoma and presents mainly at non-gastric locations even with few hepatic manifestations of the infection.

- Long-term low-grade lymphoma may present with severe disseminated disease at diagnosis, but treatment response is generally good.

\section{KEYWORDS}

Palpebral MALT B-cell lymphoma, hepatitis C infection

\section{CASE DESCRIPTION}

A 65-year-old man presented to our hospital with a 2-year history of severe bilateral proptosis and painless palpable eyelid lesions causing significant limitation of eye movement (Fig. 1). He had no fever or nocturnal diaphoresis. Physical examination was notable for cervical and axillary lymphadenopathy, several small palpable subcutaneous painless nodules in the face and moderate hepatosplenomegaly. Blood counts, serum protein electrophoresis and thyroid function were normal. The patient was positive for hepatitis $\mathrm{C}$ infection, while other blood tests were normal. Brain CT was unremarkable, while CT angiography excluded cavernous vascular malformation. Facial CT showed bilateral proptosis caused by intra- and extra-orbital infiltrative vascular lesions (Fig. 2) that extended through the temporal and masticatory spaces to the pharynx and hypopharynx causing almost complete airway obstruction (Fig. 3). The results of a palpebral biopsy were consistent with low-grade Bcl-2+ extra-nodal MALT non-Hodgkin B-cell lymphoma (Fig. 4).

Our patient was referred to the haematology department where he underwent six cycles of R-CVP (rituximab-cyclophosphamide, vincristine, prednisolone) with clinical remission at 9-month follow-up. Unfortunately, he was left with considerably reduced visual acuity in his right eye. Currently he is receiving treatment for hepatitis $C$. 


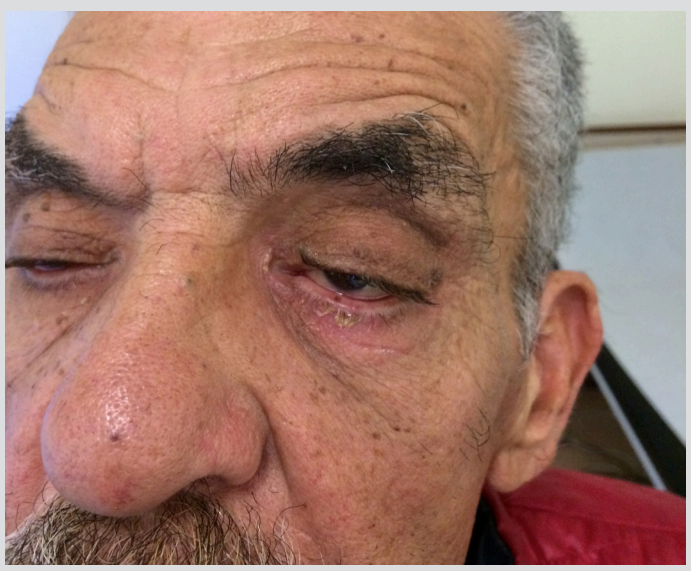

Figure 1. Patient's face showing bilateral proptosis and palpable eyelid masses

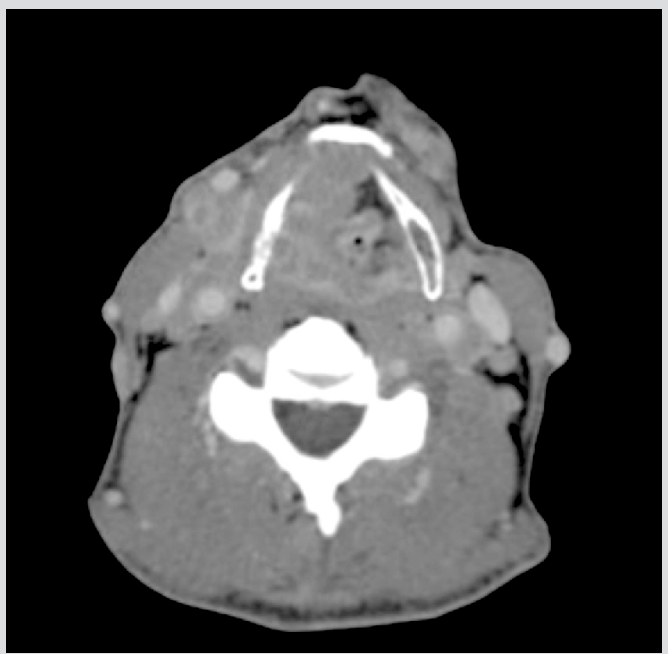

Figure 3. Neck CT showing almost complete airway obstruction by infiltrative lesions

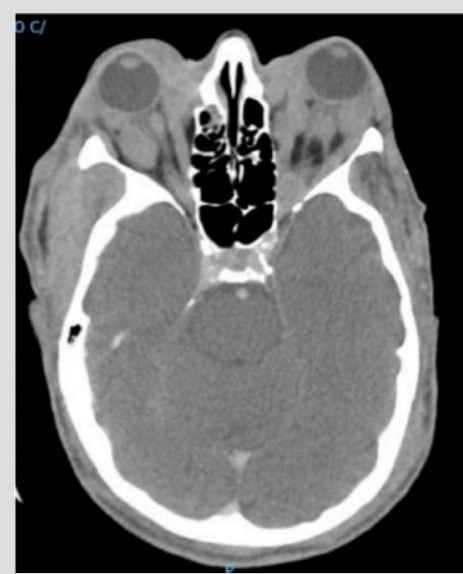

Figure 2. Facial CT showing intra- and extra-orbital infiltrative lesions

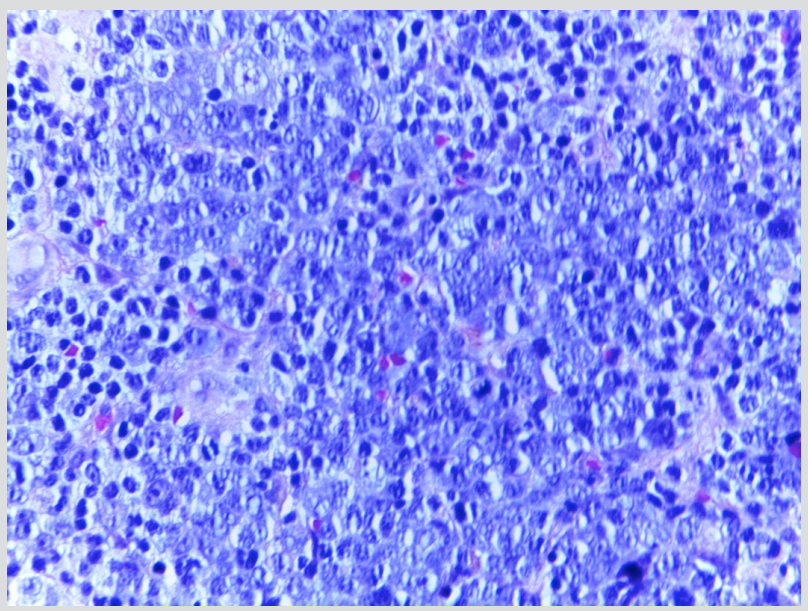

Figure 4. Palpebral biopsy showing low-grade Bcl-2+ extra-nodal MALT B-cell lymphoma

\section{DISCUSSION}

Bilateral proptosis has a broad differential diagnosis. The causes may be divided into intra-cranial pathologies and soft tissue palpebral pathologies. Intra-cranial diseases include cavernous haemangioma, fistula and meningioma. Palpebral involvement is mainly due to lymphoma, leukaemia or thyroid ophthalmopathy ${ }^{[1]}$. The diagnosis may be difficult and require invasive procedures.

MALT Iymphomas account for $5-8 \%$ of all B-cell lymphomas ${ }^{[2]}$. In hepatitis C- infected patients, MALT lymphomas are most common at non-gastric sites, often the salivary or lacrimal glands ${ }^{[2,3]}$. Chronic hepatitis $C$ may be associated with MALT lymphoma even if there are few hepatic or other extra-hepatic manifestations of infection ${ }^{[3]}$. Long-term low-grade lymphoma, as in this case, may present with severe disseminated disease. Treatment options consist of chemotherapy regimens usually based on rituximab. The overall prognosis is generally good once adequate treatment response is achieved; however, one should be aware of the increased risk of progression to diffuse large cell B-cell lymphoma whenever the disease is not in remission ${ }^{[2]}$.

\section{REFERENCES}

1. Walia SS, Stelton CR, Shantha JG, et al. Bilateral proptosis as initial manifestation of mantle cell lymphoma. Am J Med 2013;126:862-863.

2. Zucca E, Bertone F. The spectrum of MALT lymphoma at different sites: biological and therapeutic relevance. Blood 2016;127:2082-2092

3. Tasleem S, Sood GK. Hepatitis C associated B-cell non-Hodgkin lymphoma: clinical features and the role of antiviral therapy. J Clin Transl Hepatol 2015;28:134-139. 